\title{
Violência doméstica contra crianças e adolescentes: Formação e conhecimento dos médicos
}

\author{
Domestic violence against children and adolescents: Education and knowledge of physicians
}

Ayrton Margarido[a], Elisete Navas Sanches Próspero ${ }^{[b]}$, Luciane Peter Grillo[c]

\footnotetext{
${ }^{[a]}$ Mestre em Saúde e Gestão do Trabalho pela Universidade do Vale do Itajaí (Univali), docente da Graduação em Medicina do Centro Universitário São Camilo (USC), São Paulo, SP - Brasil, e-mail: dr.ayrton@terra.com.br

${ }^{\left[{ }^{[b]}\right.}$ Doutora em Enfermagem pela Universidade Federal de São Paulo (Unifesp), coordenadora do Programa de Mestrado Profissional em Saúde e Gestão do Trabalho e docente do Curso de Enfermagem da Universidade do Vale do Itajaí (Univali), Itajaí, SC - Brasil,

e-mail: enavas@univali.br

${ }^{[c]}$ Doutora em Pediatria e Ciências Aplicadas à Pediatria, docente do Programa de Mestrado Profissional em Saúde e Gestão do Trabalho e do Curso de Nutrição da Universidade do Vale do Itajaí (Univali), Itajaí, SC - Brasil,

e-mail: grillo@univali.br
}

Recebido: $16 / 02 / 2012$ Received: 02/16/2012

Aprovado: 27/03/2012 Approved: 03/27/2012

\section{Resumo}

A violência contra crianças e adolescentes sempre esteve presente na história da humanidade e é atualmente considerada um grave problema de saúde pública no Brasil, constituindo a principal causa de morte a partir dos 5 anos de idade. Trabalhar com casos de violência doméstica contra crianças e adolescentes (VDCA) não é uma tarefa fácil, uma vez que o médico pode se defrontar com situações complicadas, notadamente no Programa de Saúde da Família (PSF), que mantém estreito vínculo com comunidades inseridas em cenários propícios a esse fenômeno e expostas a risco social. Esta pesquisa exploratória, com análise qualitativa, foi desenvolvida com o objetivo de identificar a percepção de médicos atuantes no PSF sobre o processo de atendimento às vítimas de VDCA no município de São Paulo (SP). 0 estudo confirmou a falta ou do pouco conhecimento sobre as imbricações e impactos da VDCA - consequência da não abordagem do tema nos cursos de graduação e da carência de educação continuada. Além disso, revelou que os médicos dedicados a programas de atenção básica se confrontam com dilemas éticos e sentimentos que desembocam na percepção de impotência diante das vítimas de maus-tratos, associada ao medo de represálias por parte dos agressores e ao descrédito nas instituições que têm atribuição legal de dar encaminhamento aos casos. Os resultados obtidos nesta pesquisa indicam que esses fatores associados resultam em deficiências no sistema de notificação que acabam por ampliar as lacunas das estatísticas das ocorrências de violência doméstica no Brasil.

Palavras-chave: Violência. Saúde da família. Educação médica continuada.

\section{Abstract}

Violence against children and adolescents has always been present in the history of mankind, and is currently considered a severe public health problem in Brazil, where it is the major cause of death after the age of five. Working with cases of domestic violence against children and adolescents (DVCA) is a difficult task, as the doctor may have to deal with complicated situations, notably in the Family Health Program (PSF) which maintains close relationships with communities in scenarios where this phenomenon and the exposure to social risks are higher. This exploratory research, with qualitative analysis, aimed to identify the perceptions of doctors working in PSF on the process of healthcare for

Psicol. Argum. 2013 jul./set., 31 (74), 405-414 
victims of DVCA in the municipal district of São Paulo (SP). The study confirmed a lack of or insufficient knowledge of the related issues and impacts of DVCA - as a consequence of the failure of graduate courses to address the theme, and the lack of continuing education. In addition, this study reveals that doctors dedicated to basic healthcare programs face ethical dilemmas and feelings that are manifested as a sense of powerlessness to deal with victims of abuse, associated with a fear of reprisals by the aggressors and a lack of trust in the institutions that have legal attributions to refer cases. The results of this research indicate that all these factors, taken together, result in shortfalls in the reporting system that end up widening the gaps in the statistics on domestic violence in Brazil.

Keywords: Violence. Family health. Education medical continuing.

\section{A violência doméstica contra crianças e adolescentes como problema de saúde pública}

A violência é um fenômeno observado nos mais diversos contextos sociais e naturais, de múltiplas formas e nas mais diferentes coordenadas de espaço e tempo. Manifesta-se tanto na luta feroz dos animais pela defesa de seu território como na força incontrolável dos vulcões e terremotos, mas como prática deliberada ela é atributo exclusivo do homem. É pela ação desse agente que ela assume contornos de crueldade, tortura e desrespeito aos direitos humanos.

Na sociedade contemporânea ganha ênfase a violência doméstica contra crianças e adolescentes (VDCA), indo de tapinhas e puxões de orelha a "lesões abdominais, fraturas de membros, mutilações, traumatismos cranianos, queimaduras, lesões oculares e auditivas, muitas delas levando à invalidez permanente ou temporária, ou até à morte" (Minayo, 2002, p. 104).

A VDCA ocorre principalmente no ambiente intrafamiliar e doméstico e se expressa na negligência e no abandono, nos abusos sexuais e maus-tratos físicos, psicológicos, econômicos ou patrimoniais. Esse tipo de violência abrange situações de exploração sexual visando lucros (como prostituição e pornografia), rejeição, isolamento, depreciação, desrespeito, discriminação, corrupção, punições humilhantes ou cobranças exageradas do adulto em relação à criança ou ao adolescente. Em síntese, "são atos de hostilidade e agressividade que podem influenciar na imagem e autoestima da criança ou do adolescente" (Habigzang \& Caminha, 2004, p. 22).

No Brasil, a situação é alarmante. Para Azevedo e Guerra (2005, p. 15), "o retrato emergente revela um fenômeno extenso, grave, desigual e endêmico".
Com base em dados da Sociedade Internacional de Prevenção ao Abuso e Negligência na Infância (SIPANI), Valle (2007) informa que 12\% das 55,6 milhões de crianças brasileiras menores de 14 anos são vítimas de alguma forma de violência doméstica por ano. "Isso significa que 18 mil crianças são agredidas por dia, 750 por hora e 12 por minuto", afirmam Biscegli, Arroyo, Halley e Dotoli (2008, p. 366); os autores acrescentam que, "os óbitos por violência e acidentes (causas externas) ocupam o primeiro lugar na faixa etária entre cinco e 19 anos, o que significa que a violência mata mais que doenças infecciosas e parasitárias".

Quanto aos tipos de agressão infantil, Valle (2007) relata que os mais comuns são a violência física, a psicológica e a sexual e que, segundo dados do Sistema de Informação para a Infância e Adolescência (SIPIA), de 1999 até 2007 foram registrados 28.840 casos de agressão física, 28.754 de violência psicológica e 16.802 de abusos sexuais em todo o país.

O Ministério da Saúde (MS) reconhece a violência contra crianças e adolescentes como relevante problema de saúde pública. Na Proposta Preliminar de Prevenção e Assistência à Violência Doméstica (Brasil, 1997), o MS afirma que as instituições do setor de Saúde vêm sendo intensamente requisitadas para atuar nessa questão, admitindo que o fenômeno é pouco estudado e de difícil diagnose.

No documento intitulado "Violência intrafamiliar: orientações para a prática em serviço" (Brasil, 2001), o Ministério assume que o diagnóstico e o registro constituem um desafio para profissionais de todas as áreas. Nesse contexto, importa considerar, como indica Guerra (2008, p. 32), que a VDCA “tem na família sua ecologia privilegiada. Como esta pertence à esfera do privado, a violência doméstica acaba se revestindo da tradicional característica de sigilo". 
A falta de conhecimento e habilidade dos profissionais de saúde torna o diagnóstico ainda mais difícil. Isso é um indicativo de que as escolas médicas em geral não possuem uma proposta consistente para discutir o tema com a seriedade que ele requer, o que promove ainda mais o desconhecimento sobre os casos de VDCA e suas implicações sociais.

Isso traz à tona outra importante questão: apesar de o conhecimento sobre o fenômeno, ainda insuficiente e fragmentado, ser compartilhado por instituições direcionadas para ensino, pesquisa e assistência, "raramente ... os profissionais de saúde que estão voltados para o atendimento da população têm essa preocupação no atendimento e no acesso ao saber dos pesquisadores" (Brasil, 1997, p. 8).

Azevedo e Guerra (2005) consideram como um dos pontos críticos para enfrentar essa realidade o descompromisso da universidade, especialmente nos cursos de saúde, educação, direito e ciências sociais quanto à compreensão e eliminação do fenômeno da VDCA. "O resultado disso é a sua naturalização e banalização no cotidiano de todos nós e a convivência pacífica dos profissionais com uma realidade, no mínimo trágica e ultrajante, da infância e da adolescência" (Azevedo \& Guerra, 2005, p. 23).

A criação do Programa de Saúde da Família (PSF) pelo Ministério da Saúde em 1994, posteriormente Estratégia de Saúde da Família (ESF), abriu novas possibilidades de atuação do setor de saúde diante do problema da violência. A família, como o primeiro sistema de interação a que o ser humano em desenvolvimento é exposto, torna-se o principal foco de atenção.

A descrição da clientela em um território definido, o incentivo à integralidade das ações, o planejamento local baseado nas necessidades de saúde da população, a atuação intersetorial, a abordagem familiar, a humanização do atendimento — premissas metodológicas da ESF — potencialmente se constituem ferramentas promissoras de enfrentamento a questões complexas da saúde coletiva (Rocha \& Moraes, 2010). A violência seria uma delas.

Por conta dessa dinâmica, os profissionais atuantes na ESF têm mais contato com a VDCA do que aqueles não familiarizados com essa prática, porque, apesar de a violência ser democrática e atingir todas as camadas sociais, as equipes estão próximas das comunidades mais vulneráveis e em situação de risco. 0 médico componente da equipe deve utilizar em suas práticas diárias uma abordagem biopsicossocial, capaz de conciliar as suas atividades específicas com aquelas comuns a todos os membros da equipe de saúde, conforme preconiza a Política Nacional de Atenção Básica (PNAB) (Brasil, 2006).

Importa salientar que a atuação do médico na ESF requer uma relação de compromisso e de corresponsabilidade com os usuários dos serviços, o que exige habilidades especiais que vão além do saber institucionalizado. Para Scherer, Marino e Ramos (2005), esse aspecto envolve dificuldades para a operacionalização da proposta, uma vez que exige uma equipe capacitada para trabalhar de forma articulada às várias políticas sociais e recursos de forma a contribuir para a identificação das causalidades e da diversidade dos fatores que influenciam na vida da população. A esse respeito, Amoretti (2005, p. 140) sustenta que

para o sucesso da ESF são necessários médicos com características particulares: generalistas, aptos a diagnosticar e tratar a maioria das doenças prevalentes em cada região, e médicos de família e comunidade, capazes de se inserir num bairro, lidar com indicadores epidemiológicos e qualitativos próprios da assistência às pessoas, com cobertura populacional, e promover as práticas de vigilância em saúde.

Ao abordar essa questão, tomando por base as diretrizes da PNAB, Albuquerque (2006, pp. 51-52) observa que o profissional de saúde disponível no mercado de trabalho "não se encontra preparado para atuar em conformidade com as diretrizes propostas, configurando-se em um dos mais importantes obstáculos a serem superados". Para a autora, a (re)formação dos profissionais é um dos maiores desafios para a implementação da Estratégia Saúde da Família.

Por possibilitar a articulação com outros níveis de atenção à saúde e por oferecer cenários nos quais os futuros profissionais podem vivenciar práticas e se aproximar da realidade da saúde pública, a ESF se configura como um valioso aliado no processo de formação médica. Para exercer com responsabilidade e ética as tarefas a ele conferidas pela ESF, esse profissional necessita estar inserido num processo de educação permanente.

Para Haddah (2007), o conceito de educação permanente se relaciona com a ideia de construção do ser e abarca tanto a aquisição de conhecimentos e aptidões como atitudes e valores, implicando aumento da capacidade de discernir e agir. Envolve, segundo Nietsche et al. (2009), um processo dinâmico

Psicol. Argum. 2013 jul./set., 31 (74), 405-414 
e dialógico que busca qualificação para uma práxis crítica e criadora.

A PNAB atribui aos governos federal, estadual e municipal as responsabilidades de estimular e viabilizar a capacitação específica dos profissionais das equipes de saúde da família. Cabe também a essas esferas articular parceiras com outras instituições para capacitação e garantia de educação permanente aos profissionais de saúde das equipes de atenção básica e das equipes de saúde da família.

As instituições acadêmicas que oferecem programas de educação permanente priorizam competências e especialidades reivindicadas pelo mercado de trabalho, tendo como ambientes preferenciais hospitais e clínicas médicas. Abre-se, assim, um hiato entre o contingente de egressos dos centros formadores e as demandas dos serviços de saúde pública - contexto que reivindica a (re)formação dos profissionais.

Na avaliação de Amâncio, Vieira e Garcia (2006, p. 162), a formação de recursos humanos para a saúde requer "articulada parceria entre as áreas da educação e da saúde, aliadas à de ciência, tecnologia e inovação em saúde, dando corpo a um movimento que afirme ser necessário romper com a prática de políticas setoriais independentes".

Almeida, Pereira e Feuerwerker (2006, p. 35) constatam que "muitas escolas/cursos das diferentes profissões estão desenvolvendo experiências nesse campo e enfrentando muitos problemas. 0 trabalho articulado em parceria nos cenários diversificados ainda é um tema crítico e prioritário a ser trabalhado".

Por esse prisma, é sensato questionar os projetos político-pedagógicos das escolas de medicina, os quais são norteados pela fragmentação dos conteúdos, pela manutenção de disciplinas que colocam no centro o saber do professor, relegando à periferia do ensino as experiências vividas pelo aluno e sua aproximação com a realidade social. Parece haver certa rejeição às propostas de atenção básica à saúde e aos serviços na rede pública, que cedem espaço à valorização de um modelo de ensino no qual os estudantes são isentados de compromisso político e responsabilidade social e a população é destituída de protagonismo.

Amâncio et al. (2006) criticam essa situação e enfatizam que não é incomum que as reformas curriculares pretendidas ou praticadas na esfera da formação para a saúde encontrem resistências e acabem por se limitar a mudanças na nomenclatura de disciplinas. Podem também resultar na reformulação de métodos e técnicas pedagógicas, mantendo-se, porém, intactas as representações acerca do trabalho em saúde. Os autores ainda argumentam que a existência de dispositivo constitucional que estabelece para a saúde a responsabilidade pelo ordenamento da formação de seus recursos humanos não significa nem é garantia de que o setor, de maneira isolada, possa cumprir essa missão, que inclui a formação, a gestão de pessoal, os programas de educação permanente e a regulação do exercício profissional.

Farah e Pierantoni (2003) ressaltam o fato de que as ações previstas em saúde da família não foram contempladas nos currículos de formação. Como resultado, os médicos egressos utilizam o conhecimento de forma acrítica e descontextualizada, numa postura condenada por Freire (1996), cujas premissas convergem para a ideia de um contínuo processo de aprendizado, para além dos muros da universidade e articulado a um exercício diário de cidadania, capaz de contribuir para um novo modo de pensar e agir em saúde.

Ao analisar esses aspectos, Farah e Pierantoni (2003) acentuam que o atual cenário da saúde pública impõe que a saúde de família seja colocada na agenda de priorização das políticas públicas do país e invista maciçamente na qualificação dos recursos humanos para a gestão e implementação do novo modelo assistencial de saúde preconizado pelo MS.

Nesse cenário destaca-se a violência doméstica, sobretudo contra crianças e adolescentes, por ser um fenômeno que assola todos os cantos do planeta. E São Paulo - estado com mais de 40 milhões de habitantes, distribuídos em 645 municípios não foge à regra, segundo estudo realizado por Gawryszewsk et al. (2007).

Cabe assinalar que, por ser o comportamento violento um fenômeno sem um perfil padrão, cada região apresenta cenários sociais diferentes de violência. Fenômeno multifatorial, a violência infantojuvenil apresenta espacialidade diferencial de seus elementos constitutivos. Mir (2004, pp. 253-254), lembra que a violência

é heterogênea - em etiologia, qualidade, quantidade e impacto em suas vítimas. Violência física contra o semelhante pode ser resultado do impulso, reação ou agressão predatória, sem remorso. Violências podem ser físicas ou emocionais. A mais destrutiva não quebra ossos, mas quebra as mentes. Violência emocional não resulta na morte do corpo, mas na morte da alma. 
No estado de São Paulo, conforme estudo realizado por Gawryszewsk et al. (2007), o perfil da violência recai com maior intensidade em vítimas do sexo feminino. 0 modus operandi da violência registrada ficou dividida entre a negligência e o abuso sexual, sendo que, em mais de $50 \%$ dos casos, a violência ocorreu dentro dos lares. A propósito disso, Gro Harlem Brundtland (diretora-geral da Organização Mundial de Saúde), citada por Gawryszewsk et al. (2007, p. 22), declara:

A violência invade a vida de muitas pessoas em todo o mundo, e toca a todos nós de alguma forma. Para muitas pessoas, permanecer longe da violência é somente uma questão de trancar portas e janelas e evitar os lugares perigosos. Para outras, escapar da violência não é possível. A ameaça de violência está atrás daquelas portas - bem escondida da visão pública.

Especificamente com referência à violência contra crianças e adolescentes, o estudo de Gawryszewsk et al. (2007) verificou que o maior contingente de vítimas é composto por meninas cuja idade não ultrapassa os 8 anos. Dentre os tipos de violência praticados, destaca-se a negligência, seguida por abuso sexual e violência física. Quanto aos agressores, as mães são as que mais praticam violência contra seus filhos (crianças e adolescentes), seguidas por amigos e conhecidos, desconhecidos, pai, padrasto e outros.

Os autores da pesquisa enfatizam que esses resultados mostram o quanto a violência se encontra arraigada na família brasileira, uma vez que os familiares são responsáveis por alta frequência de atos violentos e a casa é o local com maior ocorrência de casos. Concluem que a violência coloca novos problemas para o setor saúde, ressaltando que são necessários mecanismos bem definidos não somente para a detecção dos casos, mas também para o acolhimento e encaminhamento das pessoas atendidas.

Importa considerar que, como assevera Mir (2004, p. 254), "a criança, que foi muito cedo emocionalmente negligenciada ou abandonada, durante a vida exibirá problemas afetivos e emocionais. Essa negligência emocional exerce papel capital na epidemia atual de violência insensata no país". 0 autor acrescenta que "a violência contra as crianças ainda é escamoteada e, na maioria das vezes, subvertida: os agressores viram agredidos" (Mir, 2004, p. 258). Daí a importância do trabalho dos profissionais da saúde, notadamente dos envolvidos com a ESF, não somente na notificação, mas também e principalmente na investigação dos casos de VDCA e suas implicações. Nesse contexto, o presente estudo teve como objetivo identificar a percepção de médicos atuantes no PSF sobre o processo de atendimento às vítimas de VDCA no município de São Paulo (SP).

\section{Metodologia}

Desenvolveu-se pesquisa exploratória com análise qualitativa, considerando que ela permite, por meio da construção de categorias, classificar os elementos significativos da mensagem. A análise dos dados se baseou na técnica de análise temática ou categorial, que segundo Minayo (2001, p. 105) "consiste em descobrir núcleos de sentido que compõe uma comunicação cuja 'presença' ou 'frequência' signifiquem alguma coisa para o objetivo analítico visado". Posteriormente, foi realizada análise do conteúdo conforme metodologia proposta por Bardin (1997).

O estudo foi desenvolvido na Unidade Básica de Saúde Hélio Moreira Salles (UBS), localizada na região que abrange os bairros de Vila Prudente, São Lucas e Sapopemba, localizados na Zona Leste de São Paulo. Localizada no Jardim dos Eucaliptos, no distrito de Sapopemba, essa UBS concentra seis Equipes de Saúde da Família, responsáveis pelo atendimento de 850 a 1.000 famílias, o que equivale a um total de 4.000 a 4.500 pessoas por equipe.

Os dados foram coletados por meio de entrevista semiestruturada com cinco médicos da ESF da UBS Hélio Moreira Salles. Para preservação da identidade dos participantes e com estrito respeito e acatamento às normas de ética que regem as pesquisas científicas, os profissionais foram identificados por meio de código, composto pela letra $\mathrm{M}$ e um algarismo (de 1 a 5) 0 protocolo de pesquisa foi aprovado pelo Comitê de Ética de Pesquisa com Seres Humanos da Secretaria Municipal de Saúde de São Paulo.

Com a organização do material e a qualificação das falas, foram definidos três temas para análise com duas categorias temáticas cada: 1) 0 entendimento dos médicos da ESF sobre a VDCA (tipos de VDCA, agentes que a praticam); 2) Explicação dos médicos sobre a VDCA (vulnerabilidade social e psicológica, religião e valores); 3) A formação profissional e acadêmica para atuação nos casos de VDCA (graduação e pós-graduação, educação permanente). 


\section{Resultados e discussão}

\section{0 entendimento dos médicos da ESF sobre a VDCA}

Em relação à categoria temática tipos de VDCA, os depoimentos dos médicos revelaram o entendimento da violência como um fenômeno que envolve os abusos físicos, psicológicos, sexuais, abandono e negligência, mostrando um conhecimento básico do tema, inclusive com uso de terminologias e categorias de violência doméstica encontradas na literatura. A exceção é M1, que não apresenta uma definição, limitando-se a dar exemplos: "chutes, socos, empurrões, agressões físicas em geral".

M2 diz que a VDCA "pode ser física e sexual" e, embora não cite a violência psicológica/emocional, pode-se inferir que ele a inclui na VDCA quando menciona genericamente "o abandono e os maus-tratos". M5 é mais específico: "pode ser sexual, física ou psicológica".

Interessante notar que o participante M3, além de considerar que os atos violentos "podem ser físicos, sexuais e emocionais", faz referência à "negligência com cuidados médicos". Esse aspecto é destacado por Pires e Miyazaki (2005, p. 44), que classificam como negligência física "a ausência de cuidados médicos, pelo não reconhecimento ou admissão, por parte dos pais ou responsáveis, da necessidade de atenção ou tratamento médico, ou em função de crenças ou práticas religiosas".

Já M4 define VDCA como "toda a violência física, sexual, psicológica, incluindo abuso e negligência contra a criança", considerando que "a palmada é um tipo de violência física". Sua fala denota sintonia, mesmo que superficial, com os debates que vêm se desenvolvendo no Brasil, com grande repercussão na imprensa, acerca desse elemento específico da violência, por muitos assumido como castigo moderado e aceitável como método educativo.

Apesar de apresentarem uma síntese correta das mais conhecidas características da VDCA - o que é comum para qualquer leigo minimamente informado sobre $o$ assunto - os entrevistados demonstram dificuldade em ampliar a discussão sobre o tema, limitando-se a uma conceituação primária. Isso pode ser resultado do pouco conhecimento e/ ou envolvimento deles com o problema e também da abstinência em discuti-lo cientificamente, como constatado pelo MS (Brasil, 1997).

Pode-se ainda considerar que, pela influência de uma formação biologicista, a identificação da violência se encontra geralmente correlacionada ao termo "agressão física" e aos exames físicos realizados. Muitos médicos se atêm ao que é palpável, visível, ignorando os aspectos psicológicos e culturais da violência.

No que se refere à categoria agentes que praticam a VDCA, os depoimentos indicam que os médicos entendem a violência doméstica como relacionada somente aos laços de consanguinidade e à família nuclear (pai, mãe e filhos), como revelam as seguintes falas: "violência praticada pelos pais" (M1), "uma violência que conta com a conivência dos pais e parentes ... e que também a praticam" (M2), "é aquela que é praticada pelos pais" (M3), "violência praticada por parentes" (M5).

Nota-se a ausência de conceitos ampliados de família, como o apresentado no Caderno de Atenção Básica elaborado pelo Ministério da Saúde e intitulado Violência intrafamiliar: orientações para a prática em serviço: "Chama-se família ao grupo de pessoas com vínculos afetivos, de consanguinidade ou de convivência" (Brasil, 2001, p. 13). 0 mesmo documento destaca que a violência intrafamiliar "pode ser cometida dentro ou fora de casa por algum membro da família, incluindo pessoas que passam a assumir função parental, ainda que sem laços de consanguinidade, e em relação de poder à outra" (Brasil, 2001, p. 15).

0 entendimento revelado nos depoimentos dos médicos pode ser atribuído ao fato de que, na sociedade brasileira contemporânea, o uso da punição física é ainda um instrumento bastante frequente na educação dos filhos. Trata-se de uma questão preocupante porque sugere certo grau de alienação diante de um dilema social que se agrava no país, vitimando milhões de crianças por ano, como informado por Valle (2007) e Biscegli et al. (2008) e, em muitos casos, levando à invalidez permanente ou temporária ou até à morte, como adverte Minayo (2002).

Importa ressaltar que a violência pode ser praticada por outros membros do grupo social mais restrito, sem função parental, como empregados, pessoas que convivem esporadicamente, agregados. Portanto, apesar de serem mais frequentes os relatos de violência cometida por parentes consanguíneos, o quadro atual da VDCA coloca a urgência de estudos mais aprofundados nesse contexto, com o olhar voltado para todos os sujeitos inseridos no cotidiano de convivência familiar. 


\section{Explicacãa dos médicos sobre a VDCA}

Como explicação para a VDCA, buscou-se analisar a percepção dos médicos quanto aos fatores de origem, ou seja, os elementos que integram as modalidades dessa violência. Quanto à vulnerabilidade social e psicológica, os entrevistados enfatizam o fator socioeconômico como um dos desencadeadores da VDCA, como mostram as seguintes falas: "questões socioeconômicas, como desemprego, drogadição" (M3); "acredito que o desemprego, drogadição, baixo nível cultural, enfim, fatores de risco social contribuem para o seu aumento" (M4), "o desemprego, drogas, moradia inadequada e valores de família, a ausência deles" (M5).

Os depoimentos expressam diferentes percepções das causas da violência doméstica, porém a determinação social está presente em todos eles, convergindo para a constatação de Pires e Miyazaki (2005, p. 44), de que "baixa renda, desemprego e pobreza são fatores associados a alto risco para negligência dos filhos, sendo negligência física a mais associada com pobreza". Pfromm (2002) também se refere à fragilidade e à vulnerabilidade das crianças, agravadas pelos recursos limitados de que dispõem em todos os aspectos, pelas preocupantes mudanças na família, pela presença e a tentação dos tóxicos e os crescentes riscos a eles associados e pelos infortúnios associados à pobreza.

Contudo, as desigualdades sociais não determinam a presença da VDCA nas comunidades mais pobres, porque, como enfatiza Silva (2002), a violência é um fenômeno de ordem cultural e perpassa todas as camadas sociais. Mas é preciso considerar os impactos causados pela miséria.

Ao mesmo tempo em que não há como desprezar a relevância dos aspectos econômicas no cenário da violência humana, deve-se admitir, para não incorrer no erro de supervalorização de um fator único, a influência de outras causas, também exógenas, no movediço terreno da violência infantojuvenil.

0 que se verifica é que, frequentemente, se associa pobreza e maus-tratos, atribuindo à condição de baixa renda ações de negligência e violência. Na realidade, famílias pobres encontram-se mais vulneráveis a serem denunciadas, o que não significa que casos de maus-tratos sejam exclusivos dessa faixa social; a questão é que, em famílias de classe média e alto poder aquisitivo, tudo é ocultado (Perozzi, 2007, p. 9).

No que diz respeito a religião e valores, os entrevistados fazem associação com os conceitos de educação e cultura. Ao falar sobre fatores possivelmente desencadeadores da violência, M1 declara: "Com certeza a falta de cultura dos pais ... a formação da família, pessoas sem princípios morais". A fala do médico revela que "o conceito de cultura tem sido evocado no ... desenvolvimento da educação em saúde, mas não tem sido explorado em profundidade ... pelos profissionais de saúde em geral" (Boehs, Monticelli, Wosny, Heidemann \& Grisotti, 2007, p. 307). A maioria deles continua trabalhando de forma sistemática com um conceito de cultura utilizado na antropologia até a década de 1960, envolvendo crenças, valores e práticas condicionadas ao olhar reducionista da biomedicina. Não existe uma única definição de cultura; Vaitsman (2000, p. 84), inclusive, considera que:

se entendemos por cultura um sistema de significados que cria algum tipo de identidade compartilhada ..., uma espécie de código que orienta as práticas sociais de pessoas pertencentes a vários grupos e categorias sociais dentro de uma sociedade, essa definição mais ampla deve ser ajustada aos tipos de fenômenos particulares que se pretende analisar.

A religião foi mencionada pelo participante M2 como elemento presente na problemática da VDCA. Para ele, talvez "a ausência de princípios religiosos seja a grande questão". Admite-se que a religião, a família e a opinião pública desempenham papéis importantes em toda e qualquer sociedade, pois exercem uma função de controle social. Mas nessa discussão não se pode ignorar os fanatismos religiosos e subprodutos, tais como os fundamentalismos de toda espécie e as guerras santas sustentadas na violência.

\section{Formacão profissional e acadêmica para a atuacãa nos casos de VDCA}

Em relação à formação profissional importa comentar que os médicos, em sua maioria, encontram-se despreparados para a realidade do combate à VDCA. Os entrevistados foram unânimes em afirmar que a eles não foram oferecidos, na graduação e pós-graduação de medicina, conteúdos ou disciplinas que indicassem preocupação com o ensino do fenômeno da VDCA: "Na faculdade? Nunca vi nada ... em nenhuma disciplina" (M1); "Acho que nunca vimos nada disso durante a graduação" (M2); "Nada

Psicol. Argum. 2013 jul./set., 31 (74), 405-414 
mesmo sobre o assunto ... nem uma aula ... nada" (M3); "Não foi abordado durante a minha graduação; ele só foi abordado durante a minha especialização em saúde da família" (M4); "Nem na faculdade e nem na residência" (M5).

Essas declarações ajudam a descrever um cenário pouco favorável para a atenção básica à saúde e sua principal estratégia, a saúde da família, praticamente ignorada pela matriz curricular e pelo projeto político-pedagógico dos cursos de graduação em medicina, que em maioria incentivam a especialização médica em detrimento da formação do médico generalista.

A Resolução CNE/CES n. 4/2001 (Conselho Nacional de Educação, 2001), que institui diretrizes curriculares nacionais do curso de graduação em medicina, prevê a formação de um médico generalista, promotor da saúde integral do ser humano, com compreensão dos determinantes sociais, culturais, comportamentais, psicológicos, ecológicos, éticos e legais do processo saúde-doença do indivíduo, da família e da comunidade.

Essa multiplicidade de abordagens deveria contemplar a Estratégia de Saúde da Família, já que é esta a prioridade da PNAB, e se direcionar para a formação de médicos integralistas. Mas, em geral, a grade curricular dos cursos de medicina não prioriza o tratamento humanizado e, na maioria das vezes, os recém-formados não estão preparados para desempenhar suas funções numa rede pública de saúde, onde existem diversos problemas estruturais.

Segundo Janaudis, Blasco e Freeman (2007, p. 32), a omissão das instituições universitárias para assumir um compromisso real na formação de profissionais para essa área "coloca o médico generalista no sério risco de tornar-se um profissional de segunda categoria". Para os autores, a questão é grave,

pois todos os esforços realizados para tornar o acesso à saúde um direito para todos os cidadãos apóia-se nesse profissional. Ele é o verdadeiro protagonista da atenção primária à saúde.... A afirmação da identidade da Medicina de Família e Comunidade como especialidade passa necessariamente por sua progressiva inserção universitária como disciplina acadêmica (Janaudis et al., 2007, p. 32).

Além da falta de preparo técnico e científico específicos nessa área, verifica-se a falta de programas de educação permanente, informada pelos participantes desta pesquisa. Todos citaram que nunca tiveram incentivos para a formação continuada voltada ao campo de saúde pública e mais especificamente para a abordagem da saúde da família.

0 profissional médico que se interessa pelo estudo das VDCA certamente terá grandes dificuldades no sentido de encontrar capacitação adequada e estímulo para a investigação de problemas sociais dessa natureza. Contudo, Janaudis et al. (2007) consideram haver terreno fértil para o crescimento da medicina de família, destacando o envolvimento crescente de estudantes de medicina com essa área, em grande parte decorrente de um trabalho de formação continuada de caráter não curricular.

\section{Considerações finais}

Constitui truísmo dizer que a situação da violência doméstica contra crianças e adolescentes no Brasil é alarmante e requer medidas efetivas de monitoramento, combate e prevenção, mas a tendência de banalização desse fenômeno na sociedade contemporânea impõe que se repita incessantemente o mesmo discurso.

A interface camaleônica da violência continua desafiando o saber dos profissionais de saúde e torna sua diagnose difícil. Afinal, ela resulta de vários processos, sendo produto de uma dinâmica social extremamente complexa; não tem, portanto, uma causa exclusiva e determinada. A dificuldade do diagnóstico da VDCA figura entre as maiores barreiras enfrentadas pelas equipes atuantes nessa área.

Observa-se a falta ou do pouco conhecimento sobre as imbricações e impactos da VDCA - consequência da não abordagem do tema nos cursos de graduação e da carência de programas de educação continuada. Isso reflete também na prática recorrente de ignorar sinais sutis de VDCA que poderiam levar ao registro de suspeita, eliminando a possibilidade de investigação mais apurada e transforma o sofrimento físico e os conflitos psicológicos e sociais a que são submetidas crianças e adolescentes em simples processos clínicos que se esgotam em único atendimento. Isso impede que as patologias sociais definidas como agressões e maus-tratos, traduzidas muitas vezes em negligência e abandono, sejam pensadas como um produto de uma sociedade também doente. 0 resultado disso é a banalização da violência que rouba a infância das crianças e destrói os projetos e sonhos dos jovens.

Esse cenário é bastante complicado e reivindica estudos sistemáticos sobre incidência e prevalência do 
fenômeno, que há muito tempo deixou de ser um problema de família para se transformar num sério problema de saúde pública. Entende-se que o incremento das pesquisas e dos debates sobre o tema e programas de educação continuada pode atuar como importante instrumento para reverter o quadro endêmico da violência e construir estratégias de enfrentamento sintonizadas com a realidade da saúde pública brasileira.

Ressalta-se que, para exercer as funções a eles conferidas, os médicos atuantes em programas de saúde da família necessitam de permanente atualização de conhecimentos e práticas para poderem desenvolver habilidades especiais no atendimento das demandas da atenção básica à saúde. Isso implica extrapolar os limites de saberes confinados em uma ou outra disciplina específica, na perspectiva da integralidade da assistência, da responsabilidade social e do compromisso com a cidadania.

É urgente que a saúde da família seja vista como prioridade nas políticas públicas do país e enfatizada nos cursos da área de ciências da saúde. Salientase que todos os participantes da pesquisa aqui relatada afirmaram que a eles não foram oferecidos, na graduação em Medicina, conteúdos ou disciplinas que indicassem preocupação com o ensino do fenômeno da VDCA. Informaram que nunca tiveram incentivos para a formação continuada voltada ao campo de saúde pública e mais especificamente para a abordagem da saúde da família.

Nesse sentido, as instituições de ensino superior e os órgãos vinculados à saúde, nas três esferas de governo (federal, estadual e municipal) são convocados para a consecução compartilhada de atividades de ensino, pesquisa e extensão nos diversos níveis de atenção à saúde da população.

Considera-se primordial a oferta de cursos de capacitação, articulada a uma maior integração do setor de Saúde com as demais instâncias de proteção à criança, de forma que a política nacional de atenção básica possa cumprir um de seus compromissos nucleares, o de constituir um espaço de construção de cidadania, consolidando e qualificando a ESF. Diante da gravidade do quadro endêmico da violência, não é mais admissível uma visão reducionista das problemáticas nela imbricadas e das possibilidades de atendimento à população vitimizada, sustentada num biologismo extremo que ignora os processos subjetivos e culturais que dela emergem e para ela convergem.

De pequenas ações individuais a decisões governamentais, todas as iniciativas que se fizerem com o propósito de minimizar e possivelmente suprimir a violência que se alastra e contamina o tecido social são importantíssimas e, por que não dizer, vitais. É fundamental inserir, nos currículos de Medicina e de vários outros cursos superiores, uma nova abordagem, capaz de reconhecer a complexidade e a multiplicidade de elementos que compõem a saúde humana, num esforço que se traduz em cuidado ético e visão generalista.

Pensar a VDCA é olhar a partir de um caleidoscópio de abordagens que se insinuam como convites e provocações ao debate, à investigação e à busca de soluções. Mas para assumirmos esse desafio e nos lançarmos na instigante aventura de aprender e ensinar a lidar com a violência, é preciso, como sugere o escritor português Miguel Torga (1980), primeiro quebrar a nossa luneta de horizontes pequenos e depois alargar o compasso com que habitualmente medimos o tamanho do que nos circunda, porque as barreiras são intermináveis, mas não intransponíveis.

\section{Referências}

Albuquerque, L. M. (2006). Desafios para a implementação da estratégia Saúde da Família: A (re)formação dos profissionais. Revista Brasileira de Saúde da Família, 7(10), 49-51.

Almeida, M. J., Pereira, L. A. P., \& Feuerwerker, L. (2006). A contribuição da Rede Unida para a qualificação da Saúde da Família. Revista Brasileira Saúde da Família, 7(10), 34-36.

Amâncio, A. Filho, Vieira, A. L. S., \& Garcia, A. C. P. (2006). Oferta das graduações em Medicina e em Enfermagem no Brasil. Revista Brasileira de Educação Médica, 30(3), 161-170.

Amoretti, R. (2005). A educação médica diante das necessidades sociais em saúde. Revista Brasileira de Educação Médica, 29(2), 136-146.

Azevedo, M. A., Guerra, V. N. A. (2005). Um cenário em (des)construção. In Unicef (Org.). Direitos negados: A violência contra a criança e o adolescente no Brasil. (pp. 15-27). Brasília: Unicef.

Bardin, L. (1997). Análise de conteúdo. Lisboa: Edições 70.

Biscegli, T. S., Arroyo, H. H., Halley, N. S., \& Dotoli, G. M. (2008). Violência doméstica contra crianças: Nível de conhecimento dos pais de crianças em escolas pública e privada. Revista Paulista de Pediatria, 26(4), 365-371.

Psicol. Argum. 2013 jul./set., 31 (74), 405-414 
Boehs, A. E., Monticelli, M., Wosny, A. M., Heidemann, I. B. S., \& Grisotti, M. (2007). A interface necessária entre enfermagem, educação em saúde e o conceito de cultura. Texto \& contexto - Enfermagem, 16(2), 307-314.

Brasil (2006). Ministério da Saúde. Secretaria de Atenção à Saúde. Departamento de Atenção à Saúde. Política nacional de atenção básica. Brasília: Ministério da Saúde.

Brasil (2001). Ministério da Saúde. Secretária de Políticas de Saúde. Violência intrafamiliar: Orientações para a prática em serviço. Brasília: Ministério da Saúde.

Brasil (1997). Ministério da Saúde. Violência contra a criança e o adolescente: Proposta preliminar de prevenção e assistência à violência doméstica. Brasília: Ministério da Saúde.

Conselho Nacional de Educação (2001). Câmara de Educação Superior. Resolução CNE/CES n. 4/2001 de 7 de novembro de 2001. Institui diretrizes curriculares nacionais do curso de graduação em medicina. Diário Oficial da União, Brasília, 9 nov. 2001, Seção 1, p. 38.

Farah, B. F., \& Pierantoni, C. R. (2003). A utilização da metodologia da problematização no curso introdutório para saúde da família do polo de capacitação da UFJF. Revista APS, 6(2), 108-119.

Freire, P. (1996). Pedagogia da autonomia: Saberes necessários à prática educativa. Rio de Janeiro: Paz e Terra.

Gawryszewsk, T. M., Guerschman, T. M., Hisano, M. E. S. X., Vanzeli, A. C., Baggio, M. C. R., Santos, R. C., \& Bertolini, M. S. (2007). A violência contra crianças e adolescentes. Boletim Epidemiológico Paulista, 4(37), 21-25.

Guerra, V. N. A. (2008). Violência de pais contra filhos: A tragédia revisitada. (6. ed.). São Paulo: Cortez.

Habigzang, L. F., \& Caminha, R. M. (2004). Abuso sexual contra crianças e adolescentes: Conceituação e intervenção clínica. São Paulo: Casa do Psicólogo.

Haddah, S. (2007). A educação continuada e as políticas públicas no Brasil. REVEJ@ - Revista de Educação de Jovens e Adultos, 1(0), 1-113.

Janaudis, M. A., Blasco, P. G., Haq, C., \& Freeman, J. (2007). Formando médicos para a medicina de família e comunidade. Revista Bioética, 15(1), 27-36.

Minayo, M. C. S. (Org.). (2001). Pesquisa social: Teoria, método e criatividade. (19. ed.). Petrópolis: Vozes.
Minayo, M. C. S. (2002). O significado social e para a saúde da violência contra crianças e adolescentes. In M. F. Westphal (Org.). Violência e criança. (pp. 95114). São Paulo: Edusp.

Mir, L. (2004). Guerra civil: Estado e trauma. São Paulo: Geração Editorial.

Nietsche, E. A., Backes, V. M. S., Ferraz, F., Loureiro, L., Schmidt, S. M. S., \& Noal, H. C. (2009). Política de educação continuada institucional: Um desafio em construção. Revista Eletrônica de Enfermagem, 11(2), 341-348. Recuperado em 12 maio 2010, de http:// www.fen.ufg.br/revista/v11/n2/v11n2a15.htm

Perozzi, M. (2007). Violência contra crianças está presente em qualquer classe social. Ciência e Cultura, 59 (2), 9-10.

Pfromm, S. Netto (2002). Comentário ao ECA. In M. Cury, A.F. Amaral e Silva \& E. G. Mendes (Coord.). Estatuto da criança e do adolescente comentado: Comentários jurídicos e sociais. (5. ed.). São Paulo: Malheiros.

Pires, A. L. D., \& Miyazaki, M. C. O. S. (2005). Maus-tratos contra crianças e adolescentes: Revisão da literatura para profissionais da saúde. Arquivo de Ciências da Saúde, 12(2), 42-49.

Rocha, P. C. X., \& Moraes, C. L. (2010). Violência familiar contra a criança e perspectivas de intervenção do Programa Saúde da Família: A experiência do PMF/Niterói, RJ. Ciência \& Saúde Coletiva, 16 (7), 3285-3296.

Scherer, M. D. A., Marino, S. R. A., \& Ramos, F. R. S. (2005). Rupturas e resoluções de atenção à saúde: Reflexões sobre a estratégia de saúde da família com base nas categorias kuhnianas. Interface - Comunicação, Saúde e Sociedade, 9(16), 53-66.

Silva, L. M. P. (2002). Violência doméstica contra a criança e o adolescente. Recife: Edupe.

Torga, M. (1980). Portugal. (4. ed.). Coimbra: Ed. do Autor.

Vaitsman, J. (2000). Cultura de organizações públicas de saúde: Notas sobre a construção de um objeto. Caderno de Saúde Pública, 16(3), 847-850.

Valle, L. (2007, jun. 4). 12\% das crianças brasileiras são vítimas de violência doméstica. $O$ Globo online. Recuperado em 8 jul. 2010, de http://oglobo.globo. com/pais/mat/.../296017253.asp. 